\title{
INVESTIGACIÓN/RESEARCH
}

Recibido: 22/12/2012 --- Revisado: 23/01/2013 Aceptado: 13/05/2013 --- Publicado: 15/07/2013

\section{UNA MIRADA HOLÍSTICA SOBRE J. EDGAR HOOVER: MITO Y HOMBRE}

Juan Enrique Gonzálvez Vallés ${ }^{1}$ : Universidad Camilo José Cela. España. juanen2012@gmail.com

\section{RESUMEN}

Clint Eastwood se ha erigido en uno de los directores más importantes del cine comercial estadounidense. Su trabajo en 2011 sobre la vida y obra de J. Edgar Hoover obtuvo desde las más ácidas críticas hasta los mayores parabienes. Eastwood construye un biopic de la misma manera que ya lo hizo cuando rodó "Bird"en 1988, esto es, con saltos hacia adelante y hacia atrás continuos en la historia, e incluso con saltos hacia atrás dentro de flashbacks previos. Responderemos a si esta película encaja en los estilemas hallados en la cinematografía del ínclito realizador californiano.

PALABRAS CLAVE: Clint Eastwood - J. Edgar - Hoover - Biopic - Estilema.

\footnotetext{
${ }^{1}$ Autor correspondiente:

Juan Enrique Gonzálvez Vallés: Profesor del centro de estudios Formatik, asociado a la Universidad Camilo José Cela. Miembro del Grupo de Investigación Concilium de la Universidad Complutense de Madrid. Editor adjunto de las Revistas científicas SEECI y Vivat Academia. España.

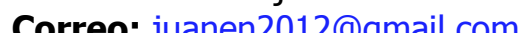




\section{a holistic view on $\mathbf{j}$. edgar hoover: myth and man}

\section{ABSTRACT}

Clint Eastwood has emerged as one of the most important directors of the American commercial cinema. His work in 2011 on the life and work of J. Edgar Hoover obtained from the most acidic to the greatest compliments reviews. Eastwood constructs a biopic of the same way it did when he shot "Bird" in 1988, that is, with leaps forward and backward continuous history, and even backflips in previous flashbacks. Respond if this movie fits into the stylistic cinematography found in the illustrious filmmaker California.

KEY WORDS: Clint Eastwood - J. Edgar - Hoover - Biopic - Stylemes.

\section{INTRODUCCIÓN}

Cada año asistimos al estreno de cientos de películas que llegan a los cines de todo el mundo. Unas cuantas de ellas, y sólo unas cuantas, son más conocidas por el nombre de quién las hace que por el propio nombre de la cinta. Son esas obras cinematográficas a las que todo el mundo se refiere como "la última de Spielberg", "la última de Tarantino" o "la última de Almodóvar". Éste también es el caso de un director y creador como Clint Eastwood.

Las nuevas producciones del ex alcalde de Carmel son esperadas y recibidas por parte del público con mucha expectativa. El recorrido como director de Eastwood ha pasado por diferentes etapas, desde el más absoluto desconocimiento de esta faceta hasta el mayor de los reconocimientos gracias a los Oscar.

\section{METODOLOGÍA}

Nuestra intención es la de que se constate y demuestre que la presencia de una sinergia entre BBVA y Carlos Soria, a través de una herramienta de las relaciones públicas externas como es el patrocinio, ha provocado que se desate en las redes sociales todo un fenómeno singular e inigualable, sobre todo partiendo de la base de que el alpinismo es un deporte minoritario.

Además, también tendremos presente la repercusión que se ha producido en los medios de comunicación, tanto analógicos como digitales. Y, por supuesto, las conexiones que se han producido entre todos estos canales, puesto que los reclamos entre unos y otros han sido lo que han producido gran parte del éxito de este caso, sobre todo por la viralidad provocada.

Para ello, realizaremos un análisis de los datos obtenidos tras el seguimiento pormenorizado de los perfiles de Carlos Soria en Facebook, Twitter y Youtube. 
Consideramos que el método expositivo y demostrativo es el más adecuado para el caso que nos ocupa, puesto que nos ayudará a obtener las conclusiones pertinentes. Además, expondremos los casos más reseñables dentro de los citados perfiles, como muestra inequívoca de lo que el público ha acogido como contenidos preferidos y predilectos.

Resulta relevante conocer todos estos puntos puesto que podremos entonces evaluar la sostenibilidad del proyecto $y$, en caso positivo, desgranar las posibles acciones futuras que se puedan llevar a cabo. Buscando, en definitiva, obtener los resultados positivos que, además, puedan ser aplicables a otros proyectos tanto dentro del mundo del deporte como en lo relacionado con otros patrocinios que ésta u otras entidades deseen llevar a cabo.

Estableciendo con claridad nuestro objetivo, estudiaremos la comunicación y la gestión de la misma que sea realizan en el proyecto de patrocinio de BBVA con Carlos Soria, focalizando sobre el estudio en las redes sociales. Al contar con tres perfiles activos (Facebook, Twitter y Youtube) podremos contemplar las diferencias fundamentales entre ellos en aspectos o indicadores de importancia como el número de seguidores, el número de impactos o el número de publicaciones en cada uno de ellos.

Con el establecimiento de los análisis que acabamos de citar también seremos testigos de cómo funcionan individualmente cada uno de estos perfiles y su relación o relaciones con sus adeptos, llámense fans, followers o suscriptores. Partiremos de la base de que en todos los perfiles se intenta transmitir siempre de la mejor manera posible, con el objetivo último de crear una imagen positiva, de la cual se beneficien los dos actores de este patrocinio, esto es, BBVA y Carlos Soria.

\section{ANÁLISIS Y DISCUSIÓN}

El último largometraje dirigido hasta el momento por Clint Eastwood es un biopic, en este caso centrado en la polémica vida de John Edgar Hoover. Eastwood basa la película en el libreto de Dustin Lance Black, un conocido guionista de Hollywood cuyas obras escritas se han basado fundamentalmente en la temática homosexual. Lance Black, de hecho, ganó el Oscar al mejor guión original por "Mi Nombre es Harvey Milk", otro biopic, en este caso sobre uno de los primeros políticos que se declararon abiertamente homosexuales.

Sobre la homosexualidad de Hoover se basa uno de los principales pilares de la película y, sin duda, el más polémico. Fue un rumor insistente en la vida de J. Edgar, puesto que nunca se casó ni tuvo ninguna relación conocida, ni mucho menos estable. Eastwood nos deja, sin embargo, una escena curiosa, con la proposición que el jefe del FBI le hace a su secretaria, Helen Gandy. La muchacha no se azora y le rechaza con la suavidad de quien sabe que lo que le ofrece Hoover es más un pacto comercial que un enlace que pueda acabar en matrimonio.

Eastwood, tras mostrar este conciso pasaje, tiene que afrontar la homosexualidad de Hoover. Lo hace de forma latente, tras el primer encuentro entre 
el jefe del FBI y Clyde Tolson, uno de los aspirantes a entrar en la oficina federal de investigación. Dejará que se siembre la duda, o más bien la certeza, entre los espectadores hasta que la resuelva de golpe y lo hará ya de forma directa y sin tapujos.

Hoover y Tolson se pelean, tras anunciar el primero su intención de proponer matrimonio a una joven. Es una secuencia arriesgada pero rodada con eficacia, Eastwood filma los golpes primero, la sumisión de Edgar después y, por último, el beso de Tolson, que intercalará con dos planos cenitales de la reacción de Edgar. Su rostro denota sorpresa pero no alcanzamos a distinguir a si lo que expresa es placer o repugnancia.

Por si no ha quedado claro, Eastwood apuntala todavía más la homosexualidad de Hoover con otra escena sorprendente. El jefe del FBI recibe con desconsuelo la noticia de la muerte de su madre, todo un icono para él y a la que ha pretendido agradar durante toda su vida. En la soledad ya de su hogar, Edgar se trasviste poniéndose el collar y el vestido de su madre.

Pero, sin lugar a dudas, el mayor mérito de Eastwood reside en la forma en la que él propone la aceptación de la homosexualidad de Hoover. No hay ni un solo plano falto de tacto o que pueda ser considerado como poco pudoroso. De hecho, sólo se exhibirá el cuerpo de uno de los dos hombres, en este caso de Edgar, cuando Tolson acude al domicilio de éste tras conocer que ha fallecido. El torso de Hoover está descubierto pero Tolson lo cubre con rapidez, quizá por respeto pero sobre todo por amor.

Más mérito todavía tiene por parte del californiano la secuencia de la última conversación entre Hoover y Tolson, en casa del segundo. Integrada sin fisuras en la historia, Eastwood la propone y le da el tratamiento de un cortometraje dentro del largometraje. Por eso la contextualiza con un plano inicial abierto, un plano general del comedor donde los dos hombres entablan conversación.

Desde ese momento, la sucesión de planos adquiere la posición de Clyde, a veces en posición semisubjetiva, a veces enfrente de su posición. Ni siquiera cuando Hoover se levanta y comienza a reprender a Tolson, Eastwood va a variar esa altura. Ampliará la gama de posiciones de la cámara y personalizará los argumentos con primeros planos que reflejan más los sentimientos de los personajes.

Después de la reprimenda inicial, Eastwood va a mostrar todavía más respeto porque llega el momento en el que Hoover declara su amor por Tolson. Tras un plano largo en cuanto a su duración que reinicia la secuencia, Eastwood aporta, ahora sí, planos semisubjetivos desde el punto de vista de Hoover que contrapone con los que ya poseía desde el punto de vista de Tolson. Son planos más agresivos, que podía haber utilizado en la discusión, pero que decide usar para aportar más romanticismo a lo que Edgar le confiesa a Tolson. 
Si bien Clyde le ha mostrado que su fidelidad le ha llevado hasta a no descubrir las mentiras que Hoover dijo sobre sí mismo para engrandecer su figura, ahora Edgar le muestra que siempre ha necesitado a Clyde, desde el mismo momento en el que le conoció, lo que remata con un beso casto en la frente de Tolson. Es Eastwood el que decide aportar, con esta secuencia, normalidad a lo que podía haber tratado de escándalo mayúsculo.

También en el plano relacional, Helen Gandy fue uno de los asideros más firmes en la vida de Hoover. Confió en ella para ser su secretaria personal y para que guardara los secretos más íntimos de casi todo el que era alguien en Estados Unidos. Interpretada por Noemi Watts, su papel e importancia es mucho menor, como realmente lo fue en la vida de J. Edgar.

Es la empleada fiel, la que pudo haber sido su esposa pero se conformó con ser su guardiana de todos los secretos atesorados por Hoover. Sus apariciones van a ser puntuales pero Eastwood le otorga un momento especial cuando el jefe del FBI le pide que destruya los archivos secretos, en caso de que a él le pase algo. Es un momento tenso pero lleno de complicidad, en el que Gandy se muestra firme en cumplir el deseo de su jefe. Volverá a ser protagonista cuando reciba la noticia de la muerte de Hoover. Eastwood sabe que ahora la importante es ella y por eso la muestra sobria y decidida a cumplir el encargo de su jefe finado.

Helen Gandy destruye documentos en un plano en contrapicado y con un ligero zoom, recurso que Eastwood sólo otorga a los protagonistas de sus películas, y que normalmente se suele reservar para sí mismo. El californiano muestra que ella es la verdadera heroína de la película, lo que subrayará con otro plano cenital de Gandy, que parece recibir el beneplácito de Hoover desde lo alto.

En cuanto a los personajes, cabe destacar también la presencia e influencia de la madre de Edgar, Annie Hoover, interpretada magistralmente por Judi Dench. Eastwood muestra el oscurantismo que transmite la progenitora de Edgar mostrándola siempre en recintos cerrados, oscuros y hasta poco ventilados.

Annie Hoover es la que continuamente le pondrá el listón a su hijo para que alcance nuevas expectativas. Las ganas de agradar a su madre será casi siempre el motivo para hacer las cosas por parte de Edgar, pero no podrá satisfacerla en cuanto a su orientación sexual. Annie muestra su completo rechazo a los homosexuales y su hijo trata de pasar de forma superficial por el tema. Pero quizás por eso, Hoover no tuvo nunca la confianza como para dar el paso de vivir con Tolson.

Eastwood lo sabe y por eso introduce la escena de trasvestismo de Hoover. El californiano asienta la condición sexual de Hoover pero, además, le hace transformarse en su propia madre, mostrando a todos que los principios de la madre de Hoover van a continuar presentes, aunque ésta ya no esté al lado del jefe del FBI.

Entrando ya en la parte técnica de la cinta, una vez más hay que hablar de la maestría a la hora de juzgar la fotografía. Tom Stern y Clint Eastwood alargan su 
escuela de pensamiento en cuanto al tratamiento fotográfico de las películas, con una sucesión de claroscuros espectaculares. La luz, como ya hemos comentado, casi no existe en los aspectos más oscuros de la vida de Hoover, como en la relación con su madre, en su trabajo en el FBI o en los encuentros con los jerifaltes de Estados Unidos.

Sin embargo, es luz lo que predomina en las escenas con Tolson, justificando una vez más con este tratamiento la relación entre los dos hombres. Pero, sobre todo, predominan los claroscuros, que dividen la cara de Edgar para mostrar y acentuar sus dos lados. La vida de J. Edgar tuvo éxitos, aportó medios y una forma correcta de trabajar al FBI, pero también acumuló información de forma dudosa que no tuvo reparo en utilizar en su propio beneficio, e incluso mintió y cometió perjurio.

Eastwood se empeña en recordarnos que no hay blancos ni negros, que las personas pueden tener dos lados casi antitéticos sin problema de conciencia y por eso construye esos claroscuros. Es una muestra más del gusto y el cuidado que tanto Stern como Eastwood aportan en fotografía a sus realizaciones, y que constituyen otro sello indiscutible de la cinematografía del californiano.

Otro de los 'hombres de Eastwood', Joel Cox, también va a realizar un trabajo sensacional en el montaje. Clint ya mostró en "Bird" que no concibe explicar la vida en un orden cronológico sin más, sino que para él la vida de una persona debe contarse aportando las respuestas a los porqués de las acciones que realiza. Esas respuestas pueden estar en el pasado o en el futuro, o puede ser necesario dando saltos hacia adelante y hacia atrás para obtener una contestación completa.

Esa es la fórmula para filmar un biopic de Clint Eastwood y eso es lo que va a volver hacer en el caso de "J. Edgar". Los flashbacks y flashforwards serán constantes hasta poder comprender la vida del director más longevo que ha tenido el FBI de forma holística. Las transiciones entre época irán desde la concatenación de situaciones y lugares, hasta las disoluciones suaves entre escenas, mostrando Eastwood y Cox un amplio y trabajado repertorio.

La música vuelve a estar a cargo del propio Clint Eastwood. Convertido en todo un hombre orquesta, el californiano se erigido en compositor musical y autor de bandas sonoras de sus películas ya casi de todas sus películas, aunque en algunas le ceda el testigo al ya mítico Lennie Niehaus.

No será en una composición musical demasiado explícita a lo largo de la cinta, sino que acompaña a la escena de forma natural y sin deshacer el grado de escritura cero que tanto le gusta a Eastwood. Esa regla tendrá su excepción en la escena en la que J. Edgar Hoover y Helen Gandy visiten la biblioteca, que Edgar se encargó de ordenar. El jefe del FBI le propone un reto a su secretaria para encontrar el libro del tema que ella elija.

Eastwood refuerza el juego entre los dos acompañándolo de una composición musical al piano que acentúa lo lúdico de la situación. Las notas, rápidas y ligeras, 
acompañan a Edgar en sus rápidos movimientos a lo largo de la biblioteca, hasta que obtiene el volumen deseado. Ahí Clint pone el punto final a este ex cursus musical para regresar a una composición que, como hemos apuntado, acompaña al argumento sin estar por encima de éste.

Si la forma de afrontar la homosexualidad de Hoover fue un tema polémico, también lo fue el maquillaje de los actores. Lo primero que hay que apuntar es que, por primera vez desde que empezara a dirigir en 1.971, Eastwood se tiene que enfrentar con el reto del envejecimiento a través del maquillaje. Enemigo acérrimo de las pinturas, Eastwood suele lucir su rostro limpio en sus películas y sus personajes, hasta esta película, no habían necesitado de un envejecimiento para su interpretación.

Las críticas en algún caso fueron feroces: "La solemne dirección de Eastwood, el torpe guión (...) y el cadavérico maquillaje de envejecimiento conspiran para distanciarse de la narración histórica y emocional. Es como un trabajo en cera parcialmente animado'"

Otras sólo apuntaron hacia este aspecto: "Las dos grandes pegas a esta película (por otra parte, impecable): se queda en segundo plano lo esencial (Kennedy, Nixon, Luther King...) y la necesidad de un maquillaje terrible" ${ }^{\prime 3}$.

Y otras que vieron en el maquillaje la oportunidad para descubrir buenas interpretaciones: "A pesar de estar sepultado bajo capas de látex, DiCaprio es una rugiente maravilla como J. Edgar Hoover. Incluso aunque la película falla en sus grandes ambiciones, no te la puedes quitar de la cabeza'A.

Al margen de esta pequeña crítica sobre la labor del departamento de maquillaje, la película recibió una buena acogida. No alcanzó ni de lejos las cifras de "Gran Torino", con 135 millones de dólares recaudados, pero con 79 millones, recaudó más del doble de lo que costó producirla, 35 millones de dólares.

Eso sí, donde fue ninguneada fue en el apartado de premios. Los Oscar no la tuvieron en cuenta y los Globos de Oro sólo le otorgaron una nominación a Leonardo DiCaprio como mejor actor dramático que no pasó de ahí. Quede como anécdota que la Broadcast Film Critics Association nominó la película en el apartado de mejor maquillaje, aunque tampoco obtuvo el galardón.

\subsection{Sinopsis}

Al más puro estilo Eastwood arranca "J. Edgar". Un plano general nos sitúa en el que va a ser el centro neurálgico donde se desarrolle la trama principal de la

\footnotetext{
${ }^{2}$ Morgenstern, J. (2011): 'J. Edgar': Hoover's Life, in a Dramatic Vacuum. Disponible en web: http://on.wsj.com/teNmNZ Consultado el 16 de noviembre de 2012.

${ }^{3}$ Rodríguez Marchante, E. (2012): "J. Edgar". Disponible en web: http://bit.ly/A4ELJi Consultado el 11 de diciembre de 2012.

${ }^{4}$ Travers, P. (2011): "J. Edgar". Disponible en web: http://bit.ly/ujamH2 Consultado el 11 de diciembre de 2012.
} 
película: un gran edificio con la bandera de Estado Unidos en la fachada principal. Una voz en off habla del comunismo como enfermedad y el crecimiento de la delincuencia y la falta de respeto por las autoridades terminarán sumiendo a la nación en la anarquía.

J. Edgar Hoover aparece por primera vez en escena sentado en el sillón de cuero de su despacho desde el que mantiene una acalorada conversación con Robert Irwin. A través de ella conocemos los primeros aspectos por los que J. Edgar fue conocido y pasó a la historia: la notoriedad como base de la fama. La señorita Gandy le comunica que un escritor le está esperando. J. Edgar ha decidido que es hora de que esta generación conozca su versión de los hechos. Hechos que vamos a conocer en un flashback que comienza con la siguiente escena.

Situados en 1.919, J. Edgar nos presenta, mediante voz en off que relata la historia, al Agente Smith, que fue su primer jefe en el Departamento de Justicia, el Fiscal General A. Mitchell Palmer. Una bomba hace volar por los cielos gran parte de la casa del señor Palmer con toda su familia en el interior. Afortunadamente no ocurre ninguna desgracia, únicamente daños materiales. La lucha de Palmer contra los radicales, los comunistas bolcheviques, había tenido este atentado como consecuencia. Toda la secuencia está caracterizada por un destacado claroscuro que apenas nos permite averiguar qué está ocurriendo. Un joven J. Edgar sale de un edificio en bicicleta y se dirige hacia el lugar de los hechos. Todas las huellas fueron borradas. Aún no existía el FBI.

Volviendo al presente, vemos por primera vez a J. Edgar junto al escritor que va a dejar plasmada en papel la versión de los hechos de Hoover. Una serie de planos en contrapicado destacan la categoría de un personaje sobre el otro. Hoover manda y para él lo que determina el legado de un hombre es lo que no se ve y quiere que quede clara la diferencia entre héroe y villano. El Agente Smith y J. Edgar se despiden hasta el día siguiente.

Un nuevo flashback nos sitúa de nuevo en una época anterior. Una secretaria le comunica a John que el Señor Palmer quiere que asista a una reunión de emergencia. Se produce en este momento el primer encuentro entre Hoover y Helen Gandy, la nueva secretaria, a la que le da la bienvenida al Departamento de Justicia.

En la siguiente escena conocemos a la madre de J. Edgar. Cuando se encuentran sus miradas se produce un flashback, dentro del flashback en el que nos encontramos, en el que la madre le habla a un Edgar niño de una premonición que dice que su padre va a morir pronto, y cuando lo haga él se convertirá en el hombre más poderoso del país.

En su reunión con el Señor Palmer, éste le ha pedido que dirija una división para luchar contra los radicales bolcheviques, aunque no aceptará el trabajo si no tiene la certeza de ser eficaz. La conversación con su madre acaba contándole Edgar la cita que tiene esa misma noche con la nueva mecanógrafa, Helen Gandy. El encuentro se 
produce en la Biblioteca del Congreso, donde Edgar va a darle a conocer el sistema de clasificación que él ayudó a crear.

Como es habitual una secuencia de planos generales nos permite conocer mejor el lugar donde se va a desarrollar la escena. Cómo funciona es lo que le explica rodeado de estanterías llenas de cajones y perdidos entre libros. El poco tiempo que tarda en encontrar un libro que ella misma le propone sirve para poner de relieve su idea sobre la identificación de los ciudadanos del país a través de una ficha con un número y su huella dactilar. A continuación él intenta besarla, pero ella le rechaza. Las intenciones de Edgar son totalmente diferentes y le pide que sea su compañera, pero para ella lo primero es su trabajo y no ambiciona casarse, por lo que acaba aceptando ser, al menos, la secretaria personal de Edgar.

Volviendo al presente, vemos la primera muestra de la fidelidad que Helen le juró a Edgar; continúa siendo su secretaria personal. El director del FBI continúa narrándole su historia al Agente Smith. Antes de llegar él al cargo existían muy pocas leyes federales y junto a Mitchell Palmer buscaron la manera de asociarse con el Departamento de Trabajo para deportar a los extranjeros, pero no encontraron ayuda porque consideraban que no había prueba de delito.

Edgar continúa contando su historia. En un nuevo flashback, en el que recuerda varios actos de los radicales que demuestran que la revolución roja había llegado a Estados Unidos, J. Edgar solicita a su equipo un informe de cada uno de los radicales del país, siempre desde la discreción y la desconfianza, para encontrar a aquellos que intenten conspirar contra el gobierno. Emma Goldman, la radical más famosa, se casó con un norteamericano, pero no tiene ningún vínculo con él y Edgar quiere demostrar que se trató de un matrimonio de conveniencia.

Con la ayuda del Señor Caminetti, el único miembro del Departamento de Trabajo que se mostró dispuesto a trabajar, se lleva a cabo un juicio contra la señora Goldman en el que, ante su negativa para responder por todos los cargos que se le imputan, el equipo de J. Edgar consigue que la sentencia sea su deportación de Estados Unidos.

Pronto comienzan las redadas por todo el país. Un nutrido grupo del Departamento de Justicia, encabezado por Edgar, viaja a la localidad de Patterson para capturar a un grupo de radicales comunistas, a los que pillan con las manos en la masa. La voz en off del propio Edgar durante el viaje de vuelta en tren junto a Helen Gandy, nos da información extra al respecto: consiguieron evitar una serie de atentados y que 500 personas fueran deportadas a su país. La consecuencia es que el país volvía a vivir en paz y, por tanto, el Sr. Palmer y otros trabajadores de Departamento de Justicia, perdieron su trabajo. Una serie de planos nos muestran la marcha de Mitchell Palmer mientras la voz en off cuenta cómo ocurrió. Así enlaza Clint la historia de nuevo con la actualidad en la que Edgar continúa contándosela al escritor, al que no echaron en aquel momento porque sólo recibía órdenes. 
Su carácter especial lleva a Edgar a cambiar el escritor de sus memorias. Ahora le cuenta cómo llegó a su cargo. Harlan Fiske Stone, el nuevo Fiscal General por aquel entonces, le citó en su despacho y le propuso ser el Director en funciones de la Oficina de Investigación. Edgar acepta con unas condiciones: que la Oficina esté totalmente desvinculada de la política y sólo responda ante él, Fiske Stone. Así empezó por despedir a todos los agentes que no cumplían sus requisitos: formación, preparación física y lealtad. Después de ser nombrado Director del FBI su madre le muestra su reconocimiento regalándole el anillo de la familia.

En una comida con compañeros se produce el primer encuentro entre J. Edgar Hoover y Clyde Tolson. De primeras coinciden en que ambos se licenciaron en la Universidad George Washington, y se intercambian las tarjetas de visita.

Ya en su despacho de director, junto a Helen, su secretaria, repasan los currículos que han recibido para optar a un puesto en la Oficina. El de Tolson es uno de ellos y, aunque a priori Gandy considera que no es adecuado para el puesto, su currículum adjunta una carta de recomendación del Ayudante Ejecutivo del Secretario de Guerra. Esto acaba por convencer a Edgar para realizarle una entrevista. La reunión con su secretaria acaba con un pacto entre ambos: Gandy creará un archivo confidencial para guardar información de alguien con poder que Edgar posee y que no quiere dejar en los archivos generales.

La siguiente escena, de nuevo con un J. Edgar Hoover de mayor edad, viene en relación a la anterior que hemos visto, y se desarrolla en el despacho de Robert Kennedy, el Fiscal General. Hoover intenta chantajearle por unos archivos que tiene en su poder. En su persecución del crimen organizado, por petición expresa del propio Robert Kennedy, Edgar introdujo micrófonos en el sótano de una casa de Los Ángeles donde tuvo lugar una reunión comunista y, casualidades la vida, donde tuvo lugar un encuentro sexual entre una comunista alemana y su hermano, el presidente de Estados Unidos, J.F. Kennedy. Con la cínica promesa de no publicar dicha información, J. Edgar le solicita, a cambio, al Fiscal General, perseguir lo que él considera una amenaza. Kennedy considera ahora al Comunismo una amenaza exterior, no interior. Pero Edgar le dice que no quiere que le ocurra ni a él ni a su hermano lo mismo que a Mitchell Palmer, que casi pierde la vida por un atentado.

Con los pertinentes cambios realizados en el despacho de Hoover por parte de Gandy para que sus subordinados le mirasen como un ser superior, el Director del FBI realiza la entrevista a Clyde Tolson. El desparpajo y las ideas de Tolson parecen haber convencido a Hoover. Queda claro que sí en la siguiente escena, donde Edgar se prueba unos trajes aconsejado por Tolson. Un problema con el crédito por confusión de identidades con alguien que firmaba como John Hoover le lleva a cambiar su firma por la que se le conocerá a partir de ese momento: J. Edgar Hoover, que da nombre a la película.

Con su traje nuevo vuelve a la Oficina. Helen le comunica que uno de sus agentes ha sido abatido en una masacre en Kansas City. Así recuerda la situación del país en 1.930, con la amenaza del Comunismo eliminada, pero con las consecuencias 
de la Depresión, que dieron lugar al problema de los gángsters, mientras continúa con la narración de su versión de los hechos. En una misma escena en diferentes momentos se suceden varios biógrafos que Edgar va sustituyendo debido a que cree incorrectas las respuestas que recibe de ellos a sus preguntas. El último le causa agrado: el hombre más famoso del siglo XX es Charles Lindbergh.

En medio de una noche, mientras dormía, J. Edgar recibe una llamada en la que le comunican que el hijo de Charles Lindbergh ha sido secuestrado. Junto a su ayudante, Clyde Tolson, J. Edgar se presenta en casa del Sr. Lindbergh. Pero se produce un encontronazo con las autoridades locales que están llevando la investigación y que le niegan el acceso a las pruebas porque Nueva Jersey, donde ocurrió el secuestro, no es de la jurisdicción del presidente que les había autorizado a ello. A su regreso a Washington y ante una Comisión del Congreso de Estados Unidos, J. Edgar Hoover solicita y consigue que se apruebe una nueva ley, la Ley Lindbergh, que considere el secuestro como un delito federal

El nuevo sistema centralizado permite que el FBI tenga en su poder todas las huellas dactilares de todas las oficinas locales de todo el país. Ante la organización de una reunión por parte del nuevo presidente, Roosevelt, con J. Edgar, y tras haber escuchado rumores de una reorganización de la Oficina, el Director del FBI le pide a su secretaria que le haga una copia del expediente de la mujer del presidente. Desde el balcón de su despacho asiste al desfile presidencial del propio Roosevelt, y en un flashforward, vuelve al interior de su despacho, en una continuación de la narración de su historia al Agente Garrison, el último biógrafo que había contratado, en la que le cuenta que Lindbergh contrató a delincuentes para encontrar a su hijo y a un desconocido, John Condon, para intermediar con los secuestradores.

J. Edgar hizo la guerra por su parte para investigar el secuestro del hijo de Lindbergh y creó un laboratorio técnico del FBI. Aparte de las pruebas comienzan a investigar a John Condon por si está implicado en el secuestro. En medio de la oscuridad de un cementerio se produce un encuentro entre Condon y el mensajero de los secuestradores, que le pide que entregue el dinero antes de tener noticias del niño. Ante esto, J. Edgar consigue que Lindbergh colabore para marcar los billetes y continuar participando en la investigación a través de una unidad especial dirigida por el Agente Sisk. Pero realmente Lindbergh no había confiado en el FBI.

Una noche, a través de su mediador John Condon, entrega el dinero a los secuestradores, que en una carta le explican cómo llegar hasta su hijo, que se encuentra en un pequeño barco cerca de Elizabeth Island. Sin pedir ayuda, el piloto Lindbergh se dirigió hacia el supuesto lugar, algo que conocemos a través de Hoover, que continúa con la narración de su biografía al Agente Garrison.

En ese momento entran Helen y Tolson en su despacho y J. Edgar les ordena que se lleven a cabo unas escuchas. En la siguiente escena, alguien realiza un montaje de micrófonos en la habitación de un hotel. Esto se intercala con la salida de Tolson y J. Edgar de la oficina y el inicio de un nuevo flashback que comienza con ambos subiéndose a un coche que les llevará hasta la Casa Blanca. 
En medio de la Depresión y al borde de la Segunda Guerra Mundial, con el nuevo presidente, el puesto de Hoover volvía a ser cuestionado. Pero, una vez más, el Director del FBI tenía en su poder unas grabaciones que no dejaban en buen lugar al presidente Roosevelt: su mujer le era infiel acostándose con un reputado agitador comunista. Una elipsis no nos permite asistir como espectadores a la reunión entre J. Edgar y Roosevelt, pero Clint nos cuenta lo ocurrido en una conversación posterior entre J. Edgar y Tolson. El presidente tiene miedo de una posible invasión externa y ha otorgado, de manera oculta, más poder a J. Edgar para investigar a los criminales radicales comunistas. En ese momento le pide a Clyde Tolson que sea su mano derecha, el Director Adjunto del FBI.

Dos desconocidos encuentran en medio del bosque, en las inmediaciones de la casa de Lindbergh, el cuerpo de su hijo. J. Edgar se lo cuenta a su madre, en cama, que cree que todos, incluido él, son culpables. Seis semanas después del secuestro es cuando se aprueba la Ley Lindbergh, que lo considera un delito federal. Pero J. Edgar tiene problemas para continuar desarrollando una laboral científica dentro de la Oficina y su enfrentamiento con el Fiscal General le lleva a enfrentarse al Congreso.

Es la siguiente escena, presentada con los senadores sobre una tarima y filmados en contrapicado para representar mayor presencia sobre J. Edgar, en la que éste intenta defender sus argumentos ante un Congreso que le acusa de diferentes problemas, como que es el Departamento que más gasta, que publicita su Departamento en programas de radio, o que no está suficientemente preparado para estar al frente del FBI porque no ha realizado ninguna detención.

Al sentirse solo, sin el apoyo incluso de Tolson, J. Edgar abandona el Congreso con dos órdenes claras: investigar al Senador Mc Kellar, que es el que ha encabezado el interrogatorio, y delegar de su puesto al Agente Purvis, que le ha quitado protagonismo al chivarse de que la detención de un importante criminal, John Dillinger, la llevó a cabo él y no J. Edgar. Este duro palo para Hoover coincide con la agonía de su madre enferma, a la que considera la única persona en la que puede confiar.

Una nueva serie de escenas nos muestran a un J. Edgar implicado directamente en varias detenciones para demostrarle al Congreso que era capaz también de arriesgar su vida. Y para darle relevancia a los hechos organiza una reunión con la prensa para ensalzar el trabajo del FBI.

En otra escena que tiene lugar en el despacho de J. Edgar, éste le lee a su mano derecha, Tolson, una carta que tiene en su poder y le cuenta que se la envió una reportera de la Casa Blanca, Ilamada Lorena Kickok a la mujer de Roosevelt, y que demuestra que hay un romance entre ambas. Tras ello, y mientras se dirigen al laboratorio, J. Edgar invita a Clyde a pasar un fin de semana en las carreras de caballos. 
Tras una sesión de cine, en la que vemos a una recuperada Annie Hoover junto a su hijo, se produce una muestra de cariño entre J. Edgar y Clyde. A continuación ambos acuden a un club nocturno en el que comparten mesa y copas con tres refinadas mujeres. La conversación gira en torno al caso Lindbergh, y J. Edgar les cuenta que han aparecido los primeros billetes registrados con los que se pagó el secuestro. Pero una invitación a bailar de una de las mujeres provoca una situación embarazosa para J. Edgar, que insta a Tolson a abandonar rápidamente el lugar alegando una enorme cantidad de trabajo.

En la siguiente escena, Edgar le confiesa a su madre que no le gusta bailar, y menos con mujeres. A lo que ella entiende como una confesión de homosexualidad, le contesta que un amigo suyo de la infancia se suicidó cuando todo el mundo supo que era un 'mariposón' y que preferiría tener un hijo muerto que un hijo 'mariposón'. Acto seguido le enseña a bailar y Eastwood nos lo muestra a través de una cámara picada, como si estuviera oculta, en una especie de intento de hacer saber al espectador que lo que acaba de ocurrir será un secreto entre ambos.

Las averiguaciones sobre el asesinato de Lindbergh continúan. La aparición de los billetes del rescate, y mediante una serie de entrevistas en la zona, J. Edgar y el resto de miembros del FBI y su laboratorio consiguen localizar y detener al culpable del secuestro y asesinato de Charles Lindbergh hijo, Bruno Hauptmann.

La narración de su historia al Agente Garrison, a la que aún le falta un título, se ve interrumpida por la llegada de la cinta con la grabación de la infidelidad de la mujer del presidente, que el propio Hoover analiza. El sonido se intercala con imágenes que no permiten ver con claridad lo que ocurrió. Pero el momento se ve interrumpido por una llamada en la que Hoover recibe la noticia de que han disparado al presidente. Él mismo se encarga de comunicárselo a su hermano, Robert Kennedy.

Una carrera de caballos nos sitúa en el viaje al que Edgar había invitado a Clyde a través de un nuevo flashback. De vuelta al hotel en el que ambos compartían habitación, comentan lo que ha ocurrido durante la jornada. J. Edgar le confiesa que le importa mucho y Clyde le contesta que le quiere mucho mientras se cogen la mano sentados en el sofá.

Pero algo ronda en la cabeza de J. Edgar, quizás las palabras de su madre sobre la homosexualidad, que introduce en la conversación la posibilidad de encontrar a una mujer para que sea la señora Hoover. Esto provoca una reacción de ira en Clyde y comienzan una acalorada discusión, con golpes incluidos, que acaba con Clyde besando a Edgar. Cuando siente que su mano derecha se aleja, Edgar le ruega que no se vaya y éste le dice que no quiere más amiguitas o dejará de disfrutar de su compañía.

La escena tras el flashback se desarrolla también en una carrera de caballos a la que asisten Hoover y Tolson. Éste sufre un ataque, probablemente al corazón, que le lleva a limitar sus funciones y horas de trabajo. En el momento en que reciben el 
informe médico, Hoover también se encuentra mal y le pide algún medicamento para aumentar su energía.

Mientras desayunan, J. Edgar le comunica a un desmejorado Clyde, al que además humilla porque no le entiende al hablar, la estrategia que va a llevar a cabo contra Martin Luther King, cercano a los comunistas y ganador del próximo Premio Nobel de la Paz. Una vez más J. Edgar también tiene información confidencial de este personaje y va a enviarle la grabación junto con una carta anónima el día antes de que le entreguen el Nobel; si King acepta el premio, Edgar le hará llegar dicha grabación a la prensa. Mientras, él comienza su tratamiento de 'vitaminas' para mejorar su ánimo.

En la siguiente escena, en su despacho, sólo iluminado por una lámpara de mesa, Edgar le dicta a una asustada Helen la carta que enviará a Luther King. Continúa narrando su historia a un nuevo biógrafo en el punto que se había quedado tras la detención de Bruno Hauptmann. Eastwood intercala ahora imágenes del juicio contra Hauptmann, finalmente culpable de homicidio y sentenciado a muerte, y el visionado del vídeo del mismo por Hoover y el Agente Owens. Hoover cita el reconocimiento que recibió el FBI, ensalzado como un héroe, y le comunica a Owens que quiere que ese sea el final de su historia.

De nuevo en su casa junto a Clyde, sentados frente al televisor, observan lo que emite en ese momento la televisión. J. Edgar cree que Martin Luther King va a rechazar el Premio Nobel por la amenaza que ha recibido de publicar su información confidencial, pero, estupefacto porque ocurre todo lo contrario, apaga el televisor.

Una corta escena en la que J. Edgar muestra gestos de fatiga y malestar, se sucede de otro flashback en el que Edgar asiste a la muerte de su madre. En su habitación y con su ropa y sus joyas se viste de mujer y sufre un ataque de ansiedad.

J. Edgar Hoover sigue siendo asistido por su médico para paliar los supuestos efectos del cansancio. Tras una reunión con el nuevo presidente, Nixon, Edgar le pide a Helen que, si algún día le pasa algo, por favor proteja sus archivos privados porque si no Nixon acabará con el FBI. Ella, su siempre fiel secretaria, le jura que nadie los encontrará jamás.

En una conversación posterior, mientras desayunan, entre J. Edgar y Clyde nos revelan qué se habló en la reunión entre Edgar y Nixon. Sabe lo de los archivos secretos y quiere ampliar las escuchas a la prensa. Hará lo que sea para conservar el poder. Por ello, Tolson le dice que quizás debería retirarse ahora que está en la cresta de la ola y puede hacerlo a lo grande, pero Edgar considera eso una falta de lealtad. Algo que Tolson niega diciéndole que ha leído su manuscrito y que toda la verdad está magnificada y falseada, y que puede mentir a los demás por su bien y el de la Oficina, pero no a él. Hoover le rechaza, pero acaba confesándole que el día que le entrevistó en su despacho estaba sudando porque se dio cuenta de que le necesitaba, y nunca había necesitado a nadie en su vida. Un pequeño achaque le sobreviene en ese momento, aunque Hoover lo relaciona con indigestión. Con un beso en la frente, le 
despide diciéndole que es ya la única persona en la que puede confiar; es una declaración de amor.

Una mañana, al llegar a la oficina, Helen Gandy recibe una llamada de la residencia de Hoover. Había fallecido. Helen se encierra en su despacho. En la siguiente escena el presidente Nixon también recibe la noticia, aunque ordena a sus asesores que, antes de preparar un discurso para televisión, cierre su despacho, cambie las cerraduras e intenten recuperar todos los archivos secretos.

Muy afectado por la noticia llega a su casa Tolson. Le encuentra en el suelo, donde respiró por última vez. Le tapa con la sábana de su cama y llora sobre su cadáver. Una cámara picada desde una esquina de la habitación nos hace partícipes desde la lejanía, concediéndole intimidad.

Comienza el discurso de Nixon ante la televisión y con su voz en off en un segundo plano, se produce el registro del despacho de J. Edgar Hoover por parte de los hombres del presidente, pero no encuentran nada. La siguiente imagen nos desvela qué ha ocurrido: Helen Gandy está triturando todos los documentos en la soledad de su secretaría.

En la última escena, sentado sobre la cama de J. Edgar Hoover, Clyde Tolson lee una carta que éste le había dejado escrita.

Clint Eastwood acaba con una información extra de lo que ocurrió después:

"El contenido de los archivos personales y confidenciales de Hoover nunca se sabrá. Sólo unas pocas pistas de artículos mal archivados han salido a la luz".

"Clyde Tolson heredó los bienes de Hoover, se mudó a su casa, y aceptó que la bandera de Estados Unidos cubriera su ataud".

"La tumba de Clyde Tolson está a unos pocos metros de la de Hoover en el cementerio del Congreso".

\section{CONCLUSIONES}

A la hora de establecer las pertinentes conclusiones de esta investigación debemos apuntar, como ya lo hicimos en la introducción, a las huellas permanentes o estilemas autoriales que existen en la cinematografía de Clint Easwood. Como ya introdujimos los quince estilemas que nuestros estudios previos han reflejado ${ }^{5}$, mostraremos ahora, a modo de conclusión, la relación de los mismos y su concordancia o no con esta obra cinematografía.

\footnotetext{
${ }^{5}$ Gonzálvez, J.E. (2012): "El estilema autorial en el cine de Clint Eastwood / Stylemes of the author in the cinematography of Clint Eastwood". Madrid. Universidad Complutense.
} 
1. Temática: "J. Edgar" responde al estilema de Easwood que refleja en sus películas temas del American way of life y, como en este caso, un prototipo del mismo, como la vida de J. Edgar Hoover. Además, también introduce su preocupación por los temas familiares, ejemplificándolo con la relación entre J. Edgar y su madre.

2. Género: También se ajusta esta película al estilema sobre el género en Clint Eastwood. Responde esta obra a un género clásico, el biopic o película biográfica, asentado en Hollywood casi desde que el cine es cine. Una vez más, Eastwood responde a su honorífico título del 'último de los clásicos'.

3. Secuencia de contextualización: De nuevo Eastwood vuelve a cumplir con uno de sus estilemas más fijos. El primer plano de la película es uno general del edificio del FBI donde Hoover con voz en off lo que para él es el comunismo. El segundo plano es uno panorámico desde abajo hacia arriba de la puerta principal del mismo edificio, resaltando en contrapicado la bandera de los Estados Unidos. La película está contextualizada de forma rápida y eficaz para el espectador.

4. Dosificación de la información: Es uno de los estilemas que podemos considerar que sólo se cumple en una pequeña parte, puesto que, en este caso, Eastwood trata de explicar todos los datos vitales de importancia de Hoover a través del montaje, sin apenas dosificar la información. En todo caso, podemos hablar de la misma en cuanto a las referencias a la homosexualidad de J. Edgar. El director californiano muestra sin mostrar hasta casi la mitad de la cinta el hecho de que Hoover se sienta atraído por Tolson.

5. Diálogos: Vuelven a servir a Eastwood para aportar toda la información que necesita para desarrollar los personajes de la película. Vuelve a incidir el montaje para reducir la importancia de este estilema, puesto que las analepsis y las prolepsis aportan, ya de por sí, la necesaria información para justificar los actos de los personajes.

6. McGuffin: En este caso, al tratarse de una película biográfica, es el propio protagonista el que se erige en el elemento que hace avanzar la historia.

7. Personaje fantasma: El principal es la madre de Hoover cuya presencia e influencia se hace más grande una vez que muere, más que incluso cuando está viva.

8. Personaje del perdedor: J. Edgar es el principal perdedor de esta historia, fundamentalmente porque nunca fue feliz al no reconocer su sexualidad, ni al pensar que nada era suficiente para copar las expectativas que su madre había generado sobre él. 
9. Tratamiento del héroe: Eastwood recurre al plano contrapicado para tratar a Hoover, sobre todo en las secuencias que tienen que ver con el patriotismo del jefe del FBI. El público, de esta forma, sentirá la necesidad de apoyarle en su lucha contra el comunismo y su labor para fortalecer al país.

10. Iluminación: uno de los estilemas más claros en esta película. Tom Stern, como jefe de fotografía, vuelve a remarcar la ambigüedad del ser humano con claroscuros muy marcados. De esta forma Eastwood transmite que Edgar era capaz de hacer tanto lo mejor como lo peor.

11. Montaje: otro estilema singular en esta película. Como ya hizo con "Bird" hizo recurre a los flashbacks y flashforwards para que el espectador tenga una visión holística sobre los actos vitales de J. Edgar Hoover y su justificación.

12. Plano semi-subjetivo: vuelve a ser una constante a lo largo de todo el metraje. El espectador continuará recibiendo más información que la que tienen los propios personajes.

13. Música: sin elevarla al grado de leit motiv que marque la historia, como ocurre con "Sin Perdón"o "Gran Torino", sí que acompaña sin destacar sobre el relato biográfico.

14. Dirección de actores: Eastwood vuelve a llevar a sus actores a grandes registros de interpretación. Leonardo di Caprio realiza su interpretación más madura hasta ese momento y Naomi Watts asume sin estridencias su papel de secundaria.

15. Dirección de equipo: la 'familia Malpaso' vuelve a ponerse en marcha para acometer una nueva producción y Clint Eastwood confía en sus hombres de confianza para llevarla a cabo. Nombres como Robert Lorenz, Tom Stern, Joel Cox, James Murakami o Deborah Hopper son los 'familiares' en los que Eastwood se vuelve a apoyar.

\section{REFERENCIAS}

Aguilar, C. (2009): Clint Eastwood. Cátedra, Signo e Imagen/Cineastas. Madrid.

Caldevilla, D. (2005): El sello Spielberg. Visión Libros. Madrid.

Casas, Q. (2009): Clint Eastwood. Avatares Del Último Cineasta Clásico. Ediciones Jaguar. Barcelona.

Comas, A. (2006): Clint Eastwood. Tras las huellas de Harry. T\&B Editores. Barcelona. 
Gonzálvez, J.E. (2012): "El estilema autorial en el cine de Clint Eastwood / Stylemes of the author in the cinematography of Clint Eastwood". Madrid. Universidad Complutense.

Laviana, J. C. (2009), en VV.AA. "El universo de Clint Eastwood". Notorius Ediciones. Madrid.

Morgenstern, J. (2011): 'J. Edgar': Hoover's Life, in a Dramatic Vacuum. Disponible en web: http://on.wsj.com/teNmNZ Consultado el 16 de noviembre de 2012.

Rodríguez Marchante, E. (2012): "J. Edgar". Disponible en web: http://bit.ly/A4ELJi Consultado el 11 de diciembre de 2012.

Schickel, R. (2010): Clint Eastwood. Una retrospectiva. Blume. Madrid.

Travers, P. (2011): "J. Edgar". Disponible en web: http://bit.ly/ujamH2 Consultado el 11 de diciembre de 2012.

\section{Juan Enrique Gonzálvez Vallés}

Profesor del centro de estudios Formatik, asociado a la Universidad Camilo José Cela. Miembro del Grupo de Investigación Concilium de la Universidad Complutense de Madrid. Licenciado en Periodismo con Diploma de Estudios Avanzados. Profesionalmente ha ejercido como periodista en diversos medios de comunicaciones y entidades. 